Research Article

\title{
Academic Influence of China's Sports Social Discipline Based on Bibliometrics
}

\author{
Xiuyun Cui iD \\ Physical Education College, EXi'an University of Architecture and Technology, Xi'an 710055, Shaanxi, China \\ Correspondence should be addressed to Xiuyun Cui; 99002392@sisu.edu.cn
}

Received 24 March 2021; Revised 12 April 2021; Accepted 21 April 2021; Published 19 May 2021

Academic Editor: Fazlullah Khan

Copyright $\odot 2021$ Xiuyun Cui. This is an open access article distributed under the Creative Commons Attribution License, which permits unrestricted use, distribution, and reproduction in any medium, provided the original work is properly cited.

Background. To accurately evaluate sports social discipline's academic influence in China, a model of academic influence evaluation of sports social discipline in China based on bibliometrics is proposed. Objective. A statistical model of the academic influence of sports social discipline is constructed, the word frequency statistics method is used to measure the literature, and the semantic characteristic quantity of the sports social discipline academic influence is extracted, using the literature method and logical analysis method to analyze sports' social value in the Internet era from healthy sports. The combination of sports and medical treatment can comprehensively promote physical and mental health. Methods. The dual semantic feature decomposition method is used to analyze sports social discipline's academic influence. The statistical analysis model of sports social discipline academic influence is established. The principles of fuzzy pattern recognition include the principle of maximum membership degree and proximity degree. Results. The comprehensive relative closeness of the distribution of literature statistics on sports and social disciplines' academic influence is constructed. The linear programming analysis of literature statistics is carried out using the standardized grid computing method. Conclusions. The combination of association rule feature extraction and semantic feature extraction is used to realize the quantitative calculation of literature statistics and academic influence. The simulation results show that the statistical analysis of the academic influence of sports and social discipline by this method is accurate, and the level of confidence is high.

\section{Introduction}

The university library is the university document information center, and it is the academic organization that serves teaching and scientific research. The work of the university library is an important part of school teaching and scientific research. The university library's construction and development should be adapted to the school's construction and development, and its level is an important symbol of the school's overall level. The libraries of colleges and universities should carry out the academic research and exchange activities in a planned way, and various scientific research subjects at all levels should be declared actively. Those who are in a position to do so may, according to their needs, set up their scientific research projects. University libraries should actively carry out academic exchanges at home and abroad. Qualified persons may apply for membership in international academic organizations in accordance with the relevant provisions of the State [1]. Sport is health. Based on this, scientific suggestions for national fitness in the Internet era are put forward: active participation in scientific exercise is fundamental; the improvement of physical and mental health is the core; the concept of lifelong sports is the goal. The fuzzy normal form is a formula combining multiple learning modes. This paper analyzes the recognition method of simple mode and language mode and then analyzes the sports literature data with this mode and method.

The number of papers and citations are two core indexes used to evaluate scientific research [2]. For an institution, the number of academic papers published is one of the direct measures of its scientific research output level. The number and scope of these papers cited by peers or other scientists is the best evaluation of these papers' recognition level. Bibliometrics is a library and information science branch, which 
uses mathematical and statistical methods to describe, evaluate, and predict the current situation and development trend of science and technology. Bibliometrics research abroad began in 1917 and has undergone three stages of development [3]. This paper adopts bibliometrics to study the academic influence of sports and social discipline in China. By analyzing the cowards of high-frequency keywords in literature metrology in China in the past ten years, the research structure is revealed in depth, and the dimension of research is discussed. To grasp the current situation of bibliometrics research in China in the past ten years, the research emphasis and the development trend are expected to be further grasped by the subject background and theoretical basis [4].

In the context of the above problems, this paper puts forward a model based on bibliometrics to evaluate the academic influence of sports social discipline in China. This paper constructs a statistical model of sports social discipline's academic influence, uses the word frequency statistics method to measure the literature, and extracts the semantic characteristic quantity of the sports social discipline academic influence. This paper uses dual semantic feature decomposition to analyze the academic influence of sports social discipline, and it establishes the statistical analysis model of sports social discipline academic influence. To calculate the comprehensive relative closeness of the distribution of literature statistics on the academic influence of sports and social disciplines, the linear programming analysis of literature statistics is carried out using the standardized grid computing method. Combination rule feature extraction and semantic feature extraction are used to realize the quantitative calculation of literature statistics and academic influence. Finally, a simulation experiment is carried out to demonstrate the superior performance of this method in improving the ability of literature statistics and analysis of sports and social disciplines' academic influence.

The specific contributions of this paper include the following:

(1) The statistical model of the academic influence of sports social discipline is constructed.

(2) The semantic characteristic quantity of academic influence of social discipline of physical education is extracted.

(3) This paper analyzes the academic influence of sports social discipline by using binary semantic feature decomposition.

(4) It realizes the quantitative calculation of literature statistics and academic influence.

The rest of this paper is organized as follows. Section 2 discusses literature statistical analysis and semantic feature extraction of academic influence of sports social discipline, followed by analysis on evaluating the academic influence of sports social discipline in Section 3. Simulation experiment and result analysis are discussed in Section 4 and Section 5 concludes the paper with a summary and future research directions.

\section{Literature Statistical Analysis and Semantic Feature Extraction of Academic Influence of Sports Social Discipline}

2.1. Literature Statistical Analysis on the Academic Influence of Sports Social Discipline. To realize the statistical analysis of sports social discipline's academic influence, the paper first establishes the literature statistical analysis model of sports social discipline academic influence. Combined with the academic influence of sports social discipline, the paper constructs a fuzzy decision matrix. The literature statistics problem of sports social discipline's academic influence is a dual semantic decision-making problem [5]. The evaluation index set of the literature retrieval results in the social discipline's evaluation process's academic influence is $F$ pair. The rule vector set is $E_{k} \in E(k=1,2, \ldots, t)$, and the association rule of sports social discipline academic influence satisfies $P_{i} \in P(i=1,2, \ldots, m)$. The evaluation value of $P \mathrm{i}$ about the result $I_{j}$ of sports social discipline academic retrieval is obtained $r_{i j}^{(k)} \in S$, and the multiple attribute grey of sports social discipline academic literature retrieval is constructed [6]. The rank of decision matrix for evaluating the academic influence of sports and social discipline satisfies $B_{k}=\left(r_{i j}^{(k)}, 0\right)_{m \times n} \cdot\left\{\left(s_{1}, a_{1}\right),\left(s_{2}, a_{2}\right), \ldots,\left(s_{n}, a_{n}\right)\right\}$ is a set of binary feature functions describing the relationship between semantic features of academic literature retrieval in sports and social disciplines [7]. The weighted average operator $\omega=\left(\omega_{1}, \omega_{2}, \ldots, \omega_{n}\right)^{T}, \omega_{j} \in[0,1]$ of the decision model of literature metrology is defined as if the corresponding weight vector under the literature statistical retrieval scheme calculates the academic influence of various sports and social disciplines. It is given as $\left\{\left(s_{1}, a_{1}\right),\left(s_{2}, a_{2}\right), \ldots,\left(s_{n}, a_{n}\right)\right\}$ and the weighted average operator $\varphi 1$ of the decision model of literature measurement is defined as follows:

$$
\begin{aligned}
(\bar{s}, \bar{a}) & =\varphi_{1}\left(\left(s_{1}, a_{1}\right),\left(s_{2}, a_{2}\right), \ldots,\left(s_{n}, a_{n}\right)\right) \\
& =\Delta\left(\sum_{j=1}^{n} \omega_{j} \Delta^{-1}\left(s_{j}, a_{j}\right)\right)
\end{aligned}
$$

where $\sum_{j=1}^{n} \omega_{j}=1, \bar{s} \in S, \bar{a} \in[-0.5,0.5]$.

Let $\left\{\left(s_{1}, a_{1}\right),\left(s_{2}, a_{2}\right), \ldots,\left(s_{n}, a_{n}\right)\right\}$ be the keyword closeness language evaluation information in sports social science academic retrieval. The corresponding weight vector $\omega=\left(\left(\omega_{1}, a_{i}^{\prime}\right),\left(\omega_{2}, a_{2}^{\prime}\right), \ldots,\left(\omega_{n}, a_{n}^{\prime}\right)\right)^{T}, \omega_{j} \in[0,1]$ is the best ideal scheme for the literature statistical cloud grid calculation of the academic influence of sports social discipline [8]. The mean operator $\varphi 2$ is defined as follows: 


$$
\begin{aligned}
(\bar{s}, \bar{a}) & =\varphi_{2}\left(\left(\left(s_{1}, a_{1}\right),\left(\omega_{1}, a_{1}^{\prime}\right)\right),\left(\left(s_{2}, a_{2}\right),\left(\omega_{2}, a_{2}^{\prime}\right)\right), \ldots,\left(\left(s_{n}, a_{n}\right),\left(\omega_{n}, a_{n}^{\prime}\right)\right)\right) \\
& =\Delta\left(\frac{\sum_{j=1}^{n} \Delta^{-1}\left(\omega_{j}, a_{j}^{\prime}\right) \Delta^{-1}\left(s_{j}, a_{j}\right)}{\sum_{j=1}^{n} \Delta^{-1}\left(\omega_{j}, a_{j}^{\prime}\right)}\right)=\Delta\left(\frac{\sum_{j=1}^{n} \beta_{j} \beta_{j}^{\prime}}{\sum_{j}^{n} \beta_{j}^{\prime}}\right),
\end{aligned}
$$

where $\sum_{j=1}^{n} \omega_{j}=1, \bar{s} \in S, \bar{a} \in[-0.5,0.5]$. Based on this, a literature statistical analysis model of the academic influence of sports social discipline is established [9].

2.2. Semantic Feature Extraction of Academic Influence of Discipline. In the decision-making process of grey correlation degree, the weight of statistical literature retrieval for the academic influence of sports social discipline includes two parts: the evaluation factor of readers and the article of academic influence of sports social discipline. The criteria for determining the reliability of resource access for statistical purposes are as follows:

$$
S(i, j)=\frac{\sum_{u \in U_{i j}}\left(V_{u, i}-3\right)\left(V_{u, j}-3\right)}{\sqrt{\sum_{u \in U_{i j}}\left(V_{u, i}-\overline{V_{. i}}\right)^{2}} \sqrt{\sum_{u \in U_{i j}}\left(V_{u, j}-\overline{V_{. j}}\right)^{2}}} .
$$

If $s_{k} \in S$ is a keyword input phrase in the statistical literature retrieval of the academic influence of sports social discipline, then the mapping of the literature statistics dual semantic distribution features of the corresponding academic influence of sports social discipline is described as follows:

$$
\begin{gathered}
\theta: S \longrightarrow S \times[-0.5,0.5], \\
\theta\left(s_{i}\right)=\left(s_{i}, 0\right), \quad s_{i} \in S .
\end{gathered}
$$

Let the real number $\beta \in[0, T]$ be the document statistical information set based on similarity label index language evaluation set $S$. The $S=\left\{v_{1}, \ldots, v_{M}\right\}$ represent the academic influence of sports social discipline and construct the literature statistical information set of similar sports social discipline academic influence. Analysis of the phenomena that appear together in a document using technical terms that can express the subject or direction of research in a particular discipline by judging the relationship between the subjects in the subject field, the research content, and the structure of the subject is displayed. The binary semantic weight of the decision-maker of the social discipline academic influence is obtained, and the semantic feature extraction of the academic influence of the discipline is realized [10]. The comprehensive evaluation information of multiattribute grey correlation decision-making of sports social discipline academic influence is constructed. The priority evaluation matrix $W_{e}=\left(\omega_{j}^{(e)}, 0\right)$ and the index weight $W=$ $\left(\left(\omega_{1}, \beta_{1}\right),\left(\omega_{2}, \beta_{2}\right), \ldots,\left(\omega_{n}, \beta_{n}\right)\right)$ of resource retrieval under similarity constraints are calculated, respectively.

\section{Analysis on the Evaluation of the Academic Influence of Sports Social Discipline}

3.1. Literature Statistical Analysis on the Academic Influence of Sports Social Discipline. This paper presents a model for evaluating the academic influence of sports social disciplines in China based on bibliometrics. To calculate the comprehensive retrieval information recommendation matrix $\bar{R}_{i k}=$ $\sum_{j \in N_{u}} C_{i, j}^{*} R_{j k}$ and the weight of constraint index of the literature, statistical decisions of learning the academic influence of sports and social discipline are as follows:

$$
\begin{aligned}
g_{i}^{+}= & \varphi_{2}\left(\left(\left(\xi_{i 1}^{+}, \eta_{i 1}^{+}\right),\left(\omega_{1}, \beta_{1}\right)\right),\left(\left(\xi_{i 2}^{+}, \eta_{i 2}^{+}\right),\left(\omega_{2}, \beta_{2}\right)\right), \ldots\right. \\
& \left.\left(\left(\xi_{i j}^{+}, \eta_{i 1}^{+}\right),\left(\omega_{j}, \beta_{j}\right)\right)\right) .
\end{aligned}
$$

According to the above steps, the decision model of multiattribute grey correlation degree for the statistical literature retrieval of sports social discipline is constructed. On this basis, the bibliometric design is carried out [11], and the academic influence of sports social discipline is obtained. The priority control vector set for the statistical literature retrieval is as follows:

$$
\begin{gathered}
T_{i}=\frac{D_{i}^{-}}{D_{i}^{+}+D_{i}^{-}}, \\
Y_{i}=\frac{R_{i}^{+}}{R_{i}^{+}+R_{i}^{-}} .
\end{gathered}
$$

This paper adopts the method of word frequency statistics to measure the literature, extracts the semantic characteristic quantity of the academic influence of sports social discipline, uses binary semantic feature decomposition to analyze the academic influence of sports social discipline [12], and obtains the literature. Normalized results of statistical index weights are as follows:

$$
\left(r_{i j}, a_{i j}\right)=\Delta\left(\frac{\Delta^{-1}\left(r_{i j}, a_{i j}\right)}{\sum_{i=1}^{n} \Delta^{-1}\left(r_{i j}, a_{i j}\right)}\right) .
$$

To determine the optimal word frequency statistical scheme, the given decision weight is $\omega e=(1 / 3,1 / 3,1 / 3)$, and the literature statistical planning state matrix of the academic influence of sports and social discipline is obtained as follows: 


$$
\begin{aligned}
& X_{1}=\left[\begin{array}{cccc}
M & G & P & P \\
P & V P & M & P \\
G & M & G & E P \\
V G & P & P & G \\
E G & E P & V P & M
\end{array}\right], \\
& X_{2}=\left[\begin{array}{cccc}
P & M & V P & V P \\
V P & E P & G & G \\
M & G & P & V P \\
E G & V P & V P & M \\
P & V P & M & V P
\end{array}\right] \text {, } \\
& X_{3}=\left[\begin{array}{cccc}
G & P & V P & V G \\
V P & G & P & G \\
V G & V P & G & P \\
G & V G & E G & V P \\
M & V P & M & E G
\end{array}\right], \\
& \omega=\left(\begin{array}{c}
\omega_{1} \\
\omega_{2} \\
\omega_{3}
\end{array}\right)=\left[\begin{array}{cccc}
M & G & V P & P \\
V P & V G & P & G \\
G & P & M & G
\end{array}\right] .
\end{aligned}
$$

In the cloud computing environment, the related domain ontology is constructed in the form of tables and attributes, and the comprehensive relative closeness degree state function of binary semantic decision analysis is described as follows:

$$
\Delta^{-1}: S \times[-0.5,0.5) \longrightarrow[0, T] .
$$

The method of multiattribute decision-making is used to determine the optimal retrieval scheme. When $\beta \in[0, T]$ is satisfied, the distribution characteristic subset of the literature statistics of the academic influence of sports and social discipline is satisfied:

$$
\Delta^{-1}\left(s_{k}, a_{k}\right)=k+a_{k}=\beta .
$$

Let $\left(s_{k}, a_{k}\right)$ and $\left(s_{l}, a_{l}\right)$ be the fuzzy closeness vectors of the literature statistical retrieval nodes of sports and social disciplines [13]. The distance between them is expressed as follows:

$$
d\left(\left(s_{k}, a_{k}\right),\left(s_{l}, a_{l}\right)\right)=\Delta\left(\left|\Delta^{-1}\left(s_{k}, a_{k}\right)-\Delta^{-1}\left(s_{l}, a_{l}\right)\right|\right) .
$$

The comprehensive decision function of group resource retrieval is established. The fuzzy closeness degree of each object and the optimal scheme is set as $E_{k} \in E(k=1,2, \ldots, t)$ and $P_{i} \in P(i=1,2, \ldots, m)$ is a set of evaluation index weights. The formula of relative closeness is expressed as follows:

$$
\begin{aligned}
(\bar{s}, \bar{a}) & =\varphi_{1}\left(\left(s_{1}, a_{1}\right),\left(s_{2}, a_{2}\right), \ldots,\left(s_{n}, a_{n}\right)\right) \\
& =\Delta\left(\sum_{j=1}^{n} \frac{1}{n} \Delta^{-1}\left(s_{j}, a_{j}\right)\right) .
\end{aligned}
$$

Therefore, the statistical literature retrieval and the comprehensive relative closeness calculation of the sports social subject's academic influence are realized [14].

3.2. Quantitative Calculation of the Academic Influence of Disciplines. In the periodical evaluation, the impact factor is an extremely important index to evaluate the periodical, which is expressed as follows:

$$
\mathrm{IF}=\frac{d_{k-1}+d_{k-2}}{D_{k-1}+D_{k-2}}
$$

In formula (13), $d_{k-1}$ represents the number of citations of the previous year's literature; $d_{k-2}$ represents the number of cited times of the previous year's literature; $D_{k-1}$ represents the total number of articles published in the previous year; $D_{k-2}$ represents the total number of articles published in the year before the publication. However, the influence factor tends to be replaced by the $\mathrm{H}$ index, which has been developed in recent years. Moreover, it is not suitable for scholars' evaluation, which is different from the number of papers and citations of the influencing factors. $\mathrm{H}$ index is an important factor in evaluating the academic level of scholars.

The $\mathrm{H}$ index method is a new method of measurement for evaluating individual academic achievements in 2005. With the development of the evaluation of academic influence on periodicals, the index method is gradually paid attention to. Many databases such as SCI are used as conventional measurement parameters and are applied to a wide range of scientific research objects, such as multidisciplinary and interdisciplinary. In the evaluation of scholars or periodicals, the $\mathrm{H}$ index means that, in the literature statistics scope, the scholars or periodicals have at least $h$ times in $\mathrm{H}$ papers, respectively. The natural number of $\mathrm{H}$ is the largest [15].

Cloud computing, parallel computing, and distributed computing techniques are used to conduct academic statistics on the academic influence of sports social sciences. The control function of bibliometrics is as follows:

$$
T(i, j)= \begin{cases}\frac{t_{i j}-t(i, j)}{t_{i j}}, & t(i, j)<t_{i j}, \\ 0, & t(i, j) \geq t_{i j},\end{cases}
$$

where $t_{i j}$ represents the minimum total cost of scheduling in the library of academic literature information of sports social sciences. $t(i, j)$ is the expected execution time of the scheduling task $t_{i}$ when the node-set $x_{i}$ of academic literature information resources of sports and social sciences leaves and leaves the library to achieve the minimum load of academic literature information resources in sports social sciences $[16,17]$. The cost function of data storage cost of the academic literature information base of sports social sciences is obtained by reconstruction of phase space under the control of security constraints: 


$$
C(i, j)= \begin{cases}\frac{c_{i j}-c(i, j)}{c_{i j}}, & c(i, j)<c_{i j}, \\ 0, & c(i, j) \geq c_{i j} .\end{cases}
$$

$c_{i j}$ denotes the dimension of phase space reconstruction of information flow of academic literature and information resources in sports and social sciences, and $c(i, j)$ is the time delay of storing replica. According to the fractal of state reorganization [18], the efficient function $E(i, j)$ of adaptive equalization control of academic literature and information resources in sports and social sciences is described as follows:

$$
E(i, j)= \begin{cases}\frac{e_{i j}-e(i, j)}{e_{\max }-e(i, j)}, & e(i, j)<e_{i j}, \\ \frac{e_{i j}-e(i, j)}{e(i, j)-e_{\min }}, & e(i, j) \geq e_{i j} .\end{cases}
$$

A statistical analysis model of the academic influence of sports social discipline is established. It calculates the comprehensive relative closeness of the statistical literature distribution of sports social discipline's academic influence. It sets the equilibrium control parameters of the literature information resources to meet the needs of $\alpha_{1}+\alpha_{2}+\alpha_{3}+\alpha_{4}=1$. The method of feature extraction of association rules shows that the comprehensive load of document information resource configuration and access control is as follows [19]:

$$
R=w_{1} C_{i}+w_{2} D_{i}+w_{3} M_{i}+w_{4} N_{i} .
$$

When the following relationships are satisfied,

$$
F=\min \left(\sum_{i}^{N} R_{i}\right)
$$

the statistical functions of the evaluation of the academic influence of sports and social disciplines in China are obtained as follows:

$$
S(x)=\sum_{i=1}^{N} v_{i}(x) \nabla^{2} v_{i}(x)
$$

In the above equation, $\nabla$ denotes a multiattribute grey correlation degree and comprehensively deals with and realizes the literature measurement and quantitative statistical analysis of the academic influence of sports and social discipline in our country [20].

\section{Simulation Experiment and Result Analysis}

To test the academic literature statistics' performance and the evaluation of the academic influence of sports and social discipline designed in this paper, the simulation experiment is carried out. The hardware CPU of the simulation is Intel Core i7-2600, which is simulated by Matlab. The data format stored in sports and society's academic resource database is Word, PDF, EXE, etc. [21,22].
Firstly, the characteristic sampling of the data storage resource information in the sports social science academic literature resource database is carried out, and the sports and social discipline are academic. The main contents of Chinese Core Journals have been published in 1992/1996/200/2004/ 2008/2011/2014, and 8 editions were published in 2017 in many university libraries in Beijing and the National Science Library of the Chinese Academy of Sciences, the Documentation and Information Center of the Chinese Academy of Social Sciences, the Book and News Information Center of the Renmin University of China, and the Electronic Journal of Chinese academic Journals (CD-ROM). More than 100 experts and periodical workers from 27 related units, including the China Institute of Science and Technology Information, Beijing Wanfang Data Co., Ltd., and the National Library, participated in the study. This study's subjects are the data from 2003 to 2017, so the ranking lists of core journals in 2004, 2008, 2011, and 2014 are related to the main contents of Chinese Core Journals in 2004, 2008, 2011, and 2014. The sample number of document test data is 1024 . The frequency of statistical feature sampling is $12 \mathrm{KHz}$. The embedding dimension of feature space reconstruction is $m=4$, and the embedding delay of semantic feature statistics is 1.5. The list of resources collected from sports core journals is shown in Table 1 below.

Each core periodical in the selected scope was selected for citation ranking of all the literature in the sports sociology field. Combined with the $\mathrm{H}$ index definition, the $\mathrm{H}$ index values and rankings of each journal in the following table were obtained. H Index of Sports Core Journals in Sports Sociology is shown in Table 2.

From Table 2, the Journal of Beijing Sport University ranked first with $\mathrm{H}$ index of 26, in the selected range of Sports Core Periodicals in the field of sports sociology all the literature, and only 26 documents have been cited with a frequency of 26 times or more. The second is the Journal of Shanghai University of Sport; the number of $\mathrm{H}$ refers to the number 24 to be second. Suppose the $\mathrm{H}$ index is used to replace the influence factor to evaluate the periodicals. In that case, it can be considered that, in all sports core journals, the quality and influence of the Journal of Beijing Sport University and Journal of Shanghai University of Sport are the highest and the one or two. The index values above 20 are also as follows: Sports and Science, Journal of Capital University of Physical Education and Sports, China Sport Science, Sports Culture Guide, China Sport Science and Technology, and Journal of Wuhan Institute of Physical Education. Compared to the journal impact factors that only observe the average influence of first to second years, the $\mathrm{H}$ index has avoided time accumulation. It is extremely insensitive to the low cited papers, so it is more scientific in the journals' academic evaluation, especially in the frontier scientific research and key areas. Moreover, the $\mathrm{H}$ index will be more scientific and extensive in the academic evaluation of scholars. Table 2 also shows that the academic achievements in sports sociology in the relatively developed areas lead the scientific research and study of China's physical education and have played more reference and reference for the related research in other areas. 
TABLE 1: Collection of data sources list of Sports Core Journals.

\begin{tabular}{|c|c|c|c|c|}
\hline & $2005-2008$ & 2009-2011 & $2012-2014$ & $2015-2017$ \\
\hline 1 & Chin & hin & China $\mathrm{Sp}$ & $\mathrm{Cl}$ \\
\hline 2 & $\begin{array}{c}\text { Chinese Journal of Sports } \\
\text { Medicine }\end{array}$ & $\begin{array}{c}\text { Journal of Beijing Sport } \\
\text { University }\end{array}$ & $\begin{array}{c}\text { Journal of Tianjin University of } \\
\text { Sport }\end{array}$ & $\begin{array}{c}\text { ournal of Shanghai University } \\
\text { of Sport }\end{array}$ \\
\hline 3 & $\begin{array}{c}\text { Journal of Beijing Sport } \\
\text { University }\end{array}$ & $\begin{array}{c}\text { Journal of Tianjin University of } \\
\text { Sport }\end{array}$ & Sports \& Science & $\begin{array}{c}\text { Journal of Beijing Sport } \\
\text { University }\end{array}$ \\
\hline 4 & $\begin{array}{l}\text { Journal of } \\
\text { University }\end{array}$ & $\begin{array}{c}\text { Journal of Chengdu Sport } \\
\text { University }\end{array}$ & $\begin{array}{r}\text { Journal of } 1 \\
\text { Univ }\end{array}$ & Sports \& Science \\
\hline 5 & $\begin{array}{l}\text { Journal of } \\
\text { University o }\end{array}$ & Sports \& Science & $\begin{array}{c}\text { Journal of Wuhan Institute of } \\
\text { Physical Education }\end{array}$ & $\begin{array}{c}\text { Journal of Tianjin University of } \\
\text { Sport }\end{array}$ \\
\hline 6 & Sports \& Science & $\begin{array}{l}\text { Journal of Wuhan Inst } \\
\text { Physical Educatic }\end{array}$ & $\begin{array}{c}\text { Journal of Chengdu } \mathrm{S}_{\mathrm{H}} \\
\text { University }\end{array}$ & $\begin{array}{c}\text { Journal of Chengdu Sport } \\
\text { University }\end{array}$ \\
\hline 7 & $\begin{array}{r}\text { Journal } \\
\text { Institute } \\
\text { Ed }\end{array}$ & $\begin{array}{c}\text { Journal of Xi'an Physical } \\
\text { Education University }\end{array}$ & $\begin{array}{c}\text { Journal of Shanghai University } \\
\text { of Sport }\end{array}$ & $\begin{array}{c}\text { Journal of Shenyang Sport } \\
\text { University }\end{array}$ \\
\hline 8 & $\begin{array}{r}\text { Journal of Ch } \\
\text { Unive }\end{array}$ & $\begin{array}{l}\text { Journal of Shar } \\
\text { of } S\end{array}$ & $\begin{array}{r}\text { Journal of S } \\
\text { Uni }\end{array}$ & $\begin{array}{l}\text { Journal of } \\
\text { Educatio }\end{array}$ \\
\hline 9 & $\begin{array}{l}\text { Journal of } \\
\text { Educati }\end{array}$ & $\begin{array}{r}\text { Journal of S1 } \\
\text { Uni }\end{array}$ & $\begin{array}{l}\text { Journal of } \\
\text { Educati }\end{array}$ & $\begin{array}{l}\text { Journal of Wuh } \\
\text { Physical E }\end{array}$ \\
\hline 10 & $\begin{array}{l}\text { Journal of Guangzhou } \\
\text { Sport University }\end{array}$ & Sports Culture Guide & Sports Culture Guide & $\begin{array}{c}\text { Journal of Guangzhou Sport } \\
\text { University }\end{array}$ \\
\hline 11 & Sports Culture Guide & $\begin{array}{l}\text { Journal of Cap } \\
\text { Physical Educ }\end{array}$ & $\begin{array}{r}\text { Journal of Gi } \\
\text { Uni }\end{array}$ & $\begin{array}{l}\text { Journal of Cap } \\
\text { Physical Educ }\end{array}$ \\
\hline 12 & $\begin{array}{r}\text { China } \mathrm{Sp} \\
\mathrm{Te}\end{array}$ & $\begin{array}{c}\text { Journal of Guangzhou Sport } \\
\text { University }\end{array}$ & $\begin{array}{l}\text { Journal of Cap } \\
\text { Physical Educ: }\end{array}$ & Sports Cult \\
\hline 13 & $\begin{array}{l}\text { Journal of Shandong } \\
\text { Sport University }\end{array}$ & $\begin{array}{r}\text { China Spor } \\
\text { Tech }\end{array}$ & $\begin{array}{r}\text { Journal of } \\
\mathrm{U}\end{array}$ & $\begin{array}{r}\text { Journal of Sha } \\
\text { Unive }\end{array}$ \\
\hline 14 & - & $\begin{array}{c}\text { Journal of Shandong Sport } \\
\text { University }\end{array}$ & $\begin{array}{c}\text { China Sport Science and } \\
\text { Technology }\end{array}$ & $\begin{array}{c}\text { China Sport Science and } \\
\text { Technology }\end{array}$ \\
\hline 15 & - & Journal of Physical Edu & $\begin{array}{l}\text { Journal of Nanjing Sport } \\
\text { Institute(Natural Science) }\end{array}$ & Journal of Physic \\
\hline 16 & - & $\begin{array}{l}\text { Journ } \\
\text { Institu }\end{array}$ & Journal of Physical Education & $\begin{array}{l}\text { Journal of } \mathrm{N} \\
\text { Institute(Nat }\end{array}$ \\
\hline $\begin{array}{l}\text { data } \\
\text { sourc }\end{array}$ & $\begin{array}{c}2004 \text { edition of "key } \\
\text { journal of Chinese core } \\
\text { journal." }\end{array}$ & $\begin{array}{r}2008 \text { edition of "key j } \\
\text { Chinese core jour }\end{array}$ & $\begin{array}{r}2011 \text { edition of "key j } \\
\text { Chinese core jour }\end{array}$ & $\begin{array}{l}2014 \text { edition of "key } \\
\text { Chinese core jou }\end{array}$ \\
\hline
\end{tabular}

TABLE 2: $\mathrm{H}$ index of sports core journals in sports sociology.

\begin{tabular}{lcc}
\hline Ranking & Periodical name & H index \\
\hline 1 & Journal of Beijing Sport University & 26 \\
2 & Journal of Shanghai University of Sport & 24 \\
3 & Sports \& Science & 23 \\
4 & Journal of Capital University of Physical Education and Sports & 23 \\
5 & China Sport Science \\
6 & Sports Culture Guide \\
7 & China Sport Science and Technology & 22 \\
8 & Journal of Wuhan Institute of Physical Education & 21 \\
9 & Journal of Chengdu Sport University & 20 \\
10 & Journal of Tianjin University of Sport & 19 \\
11 & Journal of Guangzhou Sport University & 18 \\
12 & Journal of Nanjing Sport Institute(Natural Science) \\
13 & Journal of Physical Education & 18 \\
14 & Journal of Xi'an Physical Education University & 17 \\
15 & Journal of Shandong Sport University \\
16 & Chinese Journal of Sports Medicine \\
17 & Journal of Shenyang Sport University & 15 \\
\hline
\end{tabular}


TABLE 3: Summary of sports sociology screening results for all core journals from 2006 to 2015.

\begin{tabular}{ccccc}
\hline Time & $\begin{array}{c}\text { Selection of core periodicals in } \\
\text { each edition }\end{array}$ & $\begin{array}{c}\text { Percentage of text in core } \\
\text { periodicals/\% }\end{array}$ & $\begin{array}{c}\text { Literature screening of sports } \\
\text { sociology }\end{array}$ & $\begin{array}{c}\text { Percentage of literature in sports } \\
\text { sociology/\% }\end{array}$ \\
\hline 2006 & 253 & 38.36 & 106 & 41.31 \\
2007 & 228 & 27.56 & 120 & 51.78 \\
2008 & 268 & 26.72 & 181 & 56.17 \\
2009 & 354 & 30.59 & 146 & 43.68 \\
2010 & 285 & 21.74 & 135 & 42.15 \\
2011 & 635 & 13.52 & 143 & 46.89 \\
2012 & 601 & 26.45 & 271 & 52.31 \\
2013 & 532 & 20.14 & 246 & 41.36 \\
2014 & 406 & 19.59 & 268 & 51.78 \\
2015 & 413 & 23.78 & 216 & 49.59 \\
Total & 3975 & 23.57 & 1832 & 48.53 \\
\hline
\end{tabular}

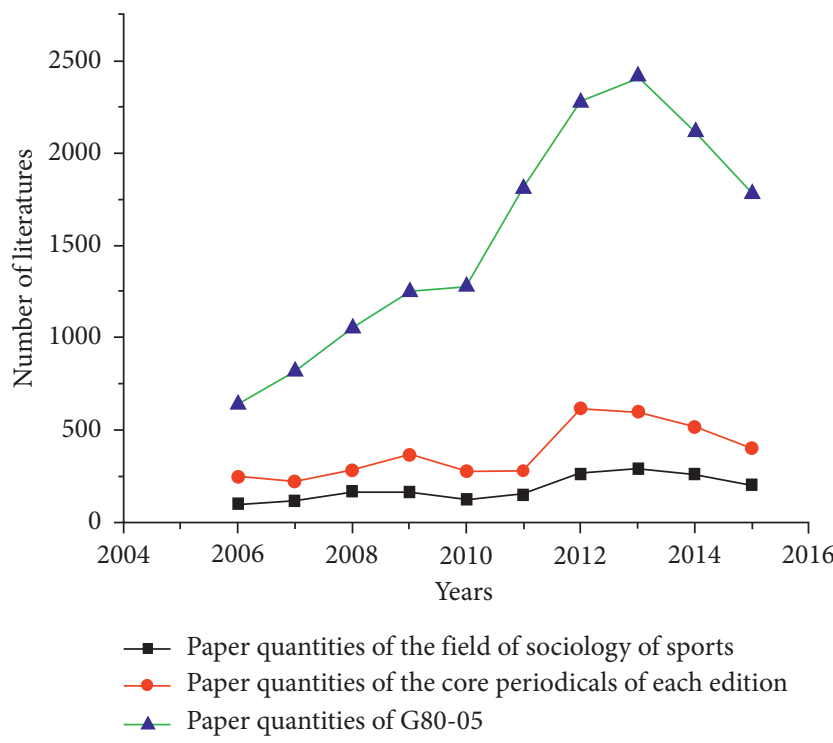

Figure 1: All sports core periodicals volume analysis of broken line chart in 2005-2015.

By screening the research results of the sports sociology in the core periodicals, through the investigation method of bibliometrics, the theme, keywords, abstracts, and contents of each research literature are analyzed in detail. The achievements in the study of sports sociology are screened out. The sports sociology leading in the core periodicals of each edition for 2006-2015 years has been completed. The amount of literature in the domain is as shown in Table 3.

Table 3 data shows that in 2006-2015 research results were associated with sports and other disciplines. The total document amount published in each edition's designated core periodicals is $38.36 \%$ and $13.52 \%$ in the highest and lowest year ratio of $23.57 \%$. The number of research results from the list of the numbers of selected articles and the numbers of research results is counted. The volume has maintained rapid growth. The reason is that the cause of the rapid increase is the successful hosting of the 2008 Beijing Olympic Games. The research enthusiasm of sports scholars on the sports industry's achievements and experience, especially the Olympic Games and the sports industry, is high, and the output is rich. Since 2011, the decline of heat has begun to fall, but the past ten years' overall research results are on the rise. A broken line graph can more clearly reflect the growth of the core journals in the past 2006-2015 years, as shown in Figure 1.

At the same time, the data of "the percentage of sports sociology literature" in Table 3 shows the 2006-2015 edition of the core periodicals. The research achievements in sports sociology have always been in a high proportion, and all the years are about $50 \%$. And even if the selected core periodicals are in the G80-05 classification retrieval conditions, sports and other disciplines related to the total load ratio fluctuate. Still, the sports sociology research results are continuous and stable and the general concern of the majority of scholars.

According to the simulation environment and parameters mentioned above, set, carry on the sports social discipline academic influence evaluation, and get the literature metrological distribution shown in Figure 2.

Figure 2 shows that the confidence level of the statistical analysis results of the literature measurement of sports and 


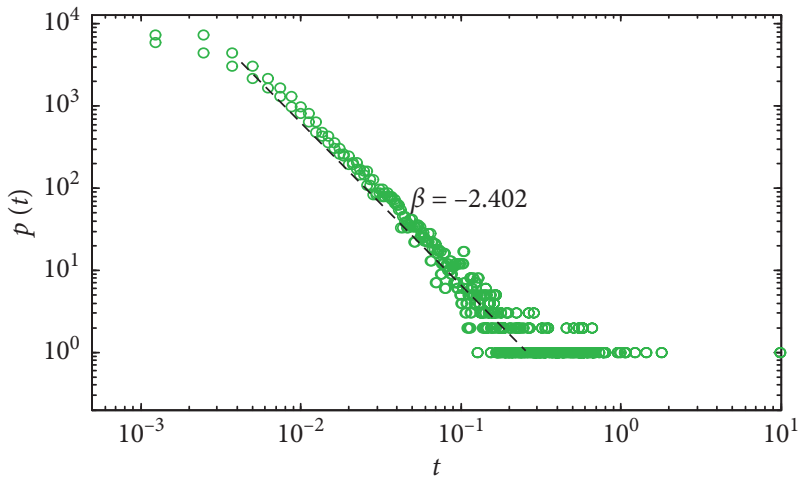

(a)

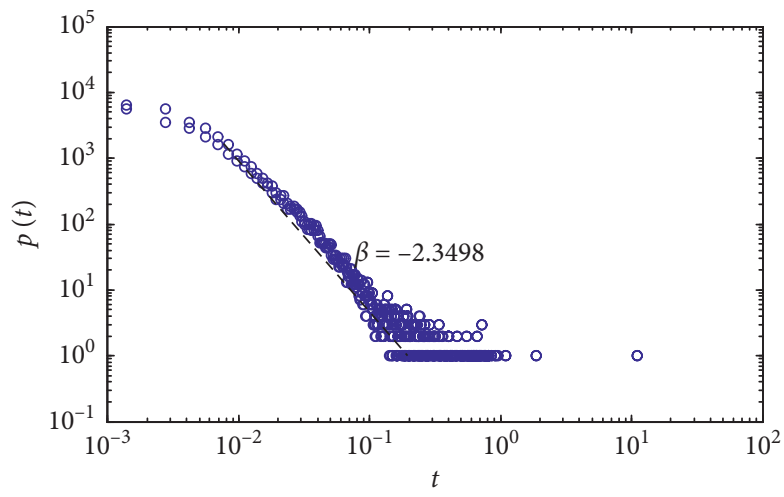

(b)

FIgURE 2: Characteristic distribution of academic influence of sports social discipline. (a) Bibliometrics method. (b) Regression analysis method.

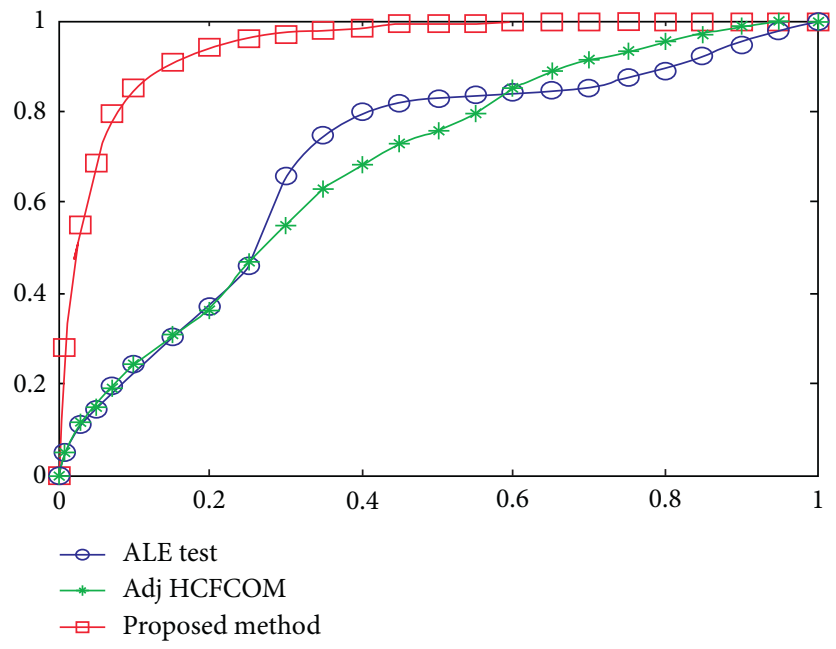

Figure 3: Accuracy of academic impact assessment.

social discipline's academic influence using this method is high. The accuracy of evaluating the mathematical influence of different methods is obtained.

The comparison results are shown in Figure 3. In this figure, this method's accuracy in evaluating sports and social discipline's academic influence is high.

\section{Conclusions}

This paper proposes a model of academic influence evaluation of sports social discipline in China based on bibliometrics. A statistical model of the academic influence of sports social discipline is constructed. The word frequency statistics method is used to measure the literature. The semantic characteristic quantity of the sports social discipline academic influence is extracted. The dual semantic feature decomposition method is used to analyze the academic influence of sports social discipline, and the statistical analysis model of sports social discipline academic influence is established. The comprehensive relative closeness of the distribution of literature statistics on the academic influence of sports and social disciplines is constructed. The linear programming analysis of literature statistics is carried out using the standardized grid computing method. The combination of association rule feature extraction and semantic feature extraction is used to realize the quantitative calculation of literature statistics and academic influence. The simulation results show that the statistical analysis of the academic influence of sports and social discipline by this method is accurate, and the level of confidence is high. This method has a good application value in the evaluation of the academic influence of physical education.

\section{Data Availability}

The datasets used and/or analyzed during the current study are available from the corresponding author on reasonable request.

\section{Conflicts of Interest}

The author declares that he has no conflicts of interest. 


\section{Acknowledgments}

This work was supported by the Social Science Foundation of Shaanxi Province (no. 2018R09).

\section{References}

[1] J. X. Cao, D. Dong, S. Xu et al., "A k core-based algorithm for influence maximization in social networks," Chinese Journal of Computers, vol. 38, no. 2, pp. 238-248, 2015.

[2] C. Wang, W. Chen, and Y. Wang, "Scalable influence maximization for independent cascade model in large-scale social networks," Data Mining and Knowledge Discovery, vol. 25, no. 3, pp. 545-576, 2012.

[3] X. Ning, Y. Luo, K. Xing, and X. Zheng, "Frequent location privacy-preserving algorithm based on geosocial network," Journal of Computer Applications, vol. 38, no. 3, pp. 688-692, 2018.

[4] N. Paragios and R. Deriche, "Geodesic active regions and level set methods for supervised texture segmentation," International Journal of Computer Vision, vol. 46, no. 3, pp. 223-247, 2002.

[5] X.-L. Jiang, Q. Wang, B. He, S.-J. Chen, and B.-L. Li, "Robust level set image segmentation algorithm using local correntropy-based fuzzy C-means clustering with spatial constraints," Neurocomputing, vol. 207, no. 4, pp. 22-35, 2016.

[6] S. Niu, Q. Chen, L. D. Sisternes et al., "Robust noise regionbased active contour model via local similarity factor for image segmentation," Pattern Recognition, vol. 61, pp. 104$119,2016$.

[7] S. Bi, C. K. Ho, and R. Zhang, "Wireless powered communication: opportunities and challenges," IEEE Communications Magazine, vol. 53, no. 4, pp. 117-125, 2015.

[8] S. Ulukus, A. Yener, E. Erkip et al., "Energy harvesting wireless communications: a review of recent advances," IEEE Journal on Selected Areas in Communications, vol. 33, no. 3, pp. 360-381, 2015.

[9] D.-W. Seo, J.-H. Lee, and H.-S. Lee, "Optimal coupling to achieve maximum output power in a WPT system," IEEE Transactions on Power Electronics, vol. 31, no. 6, pp. 39943998, 2016.

[10] A. Khabbazibasmenj, A. Hassanien, S. A. Vorobyov, and M. W. Morency, "Efficient transmit beamspace design for search-free based DOA estimation in MIMO radar," IEEE Transactions on Signal Processing, vol. 62, no. 6, pp. 14901500, 2014.

[11] P. F. Sammartino, C. J. Baker, and H. D. Griffiths, "Frequency diverse MIMO techniques for radar," IEEE Transactions on Aerospace and Electronic Systems, vol. 49, no. 1, pp. 201-222, 2013.

[12] W. Q. Wang and H. Shao, "Range-angle localization of targets by a double-pulse frequency diverse array radar," IEEE Journal of Selected Topics in Signal Processing, vol. 8, no. 1, pp. 106-114, 2014.

[13] W.-Q. Wang and H. C. So, "Transmit subaperturing for range and angle estimation in frequency diverse array radar," IEEE Transactions on Signal Processing, vol. 62, no. 8, pp. 20002011, 2014.

[14] Y. Wang, F. Zhang, G. Fang, Y. Ji, S. Ye, and X. Zhang, "A novel ultrawideband exponentially tapered slot antenna of combined electric-magnetic type," IEEE Antennas and Wireless Propagation Letters, vol. 15, pp. 1226-1229, 2016.

[15] X.-H. Lu and P. Chen, "Traffic prediction algorithm in buffer based on recurrence quantification union entropy feature reconstruction," Computer Science, vol. 42, no. 4, pp. 68-71, 2015.

[16] L. Ruihua, "Research on academic influence of scientist academic pedigree based on bibliomerics," Information Studies Theory \& Application, vol. 36, no. 14, pp. 61-73, 2017.

[17] X. Fan, Y. Gao, B. Ma, and Z. Xia, "Chinese academic contribution to burns: a comprehensive bibliometrics analysis from 1985 to 2014," Burns, vol. 42, no. 7, pp. 1463-1470, 2016.

[18] J. Yang, Y. Cui, M. Zhen, S. O. Management, and J. University, "Visualization analysis of the innovation performance's influence factors and research trend based on bibliometrics," Journal of Modern Information, vol. 53, no. 12, pp. 103-112, 2016.

[19] H. P. Cheng, "Study on the academic impact of pedagogy periodicals based on principal component analysis and entropy," Vocational Education Research, vol. 15, no. 3, pp. 7-10, 2016.

[20] H. Xue, "Status and prospect about environmental history in Chinese continental from the perspective of the bibliometric (2000-2013)-ased on the statistical and analysis of cssci," Journal of Baoshan University, vol. 31, no. 4, pp. 51-59, 2015.

[21] C. Zhao, D. Li, J. Cui, and L. Tian, "Decentralized low-order ADRC design for MIMO system with unknown order and relative degree," Personal and Ubiquitous Computing, vol. 22, no. 5-6, pp. 987-1004, 2018.

[22] Y. Sun and A. J. Jara, "An extensible and active semantic model of information organizing for the internet of things," Personal and Ubiquitous Computing, vol. 18, no. 8, pp. 1821-1833, 2014. 